2

Crow et al.

\title{
LEUKOENCEPHALOPATHY WITH CALCIFICATIONS AND CYSTS: GENETIC AND PHENOTYPIC SPECTRUM
}

Yanick J Crow ${ }^{1,2}$, Heather Marshall ${ }^{1}$, Gillian I Rice ${ }^{3}$, Luis Seabra ${ }^{2}$, Emma M Jenkinson ${ }^{3}$, Kristin Baranano $^{4}$, Roberta Battini 5,6 , Andrea Berger ${ }^{7}$, Edward Blair ${ }^{8}$, Thomas Blauwblomme ${ }^{9}$, Francois Bolduc ${ }^{10}$, Natalie Boddaert ${ }^{11}$, Johannes Buckard ${ }^{12}$, Heather Burnett ${ }^{13}$, Sophie Calvert ${ }^{14}$, Roseline Caumes ${ }^{15}$, Andy Cheuk-Him Ng${ }^{10}$, Diana Chiang ${ }^{10}$, David B Clifford ${ }^{16}$, Duccio M Cordelli ${ }^{17}$, Anna de Burca ${ }^{8}$, Natasha Demic ${ }^{18}$, Isabelle Desguerre ${ }^{19}$, Liesbeth De Waele $^{20,21}$, Alessio Di Fonzo ${ }^{22,23}$, S. Richard Dunham ${ }^{16}$, Sarah Dyack ${ }^{24}$, Frances Elmslie ${ }^{25}$, Mickaël Ferrand ${ }^{26}$, Gemma Fisher 27 , Ehsan Ghayoor Karimiani28,29, Jamal Ghoumid ${ }^{15}$, Frances Gibbon ${ }^{27}$, Himanshu Goel ${ }^{30,31}$, Hilde T Hilmarsen ${ }^{32}$,Imelda Hughes ${ }^{33}$, Anu Jacob ${ }^{34,35}$, Elizabeth A Jones ${ }^{3,36}$, Ram Kumar ${ }^{37}$, Richard J Leventer ${ }^{38,39}$, Shelley MacDonald ${ }^{40}$, Reza Maroofian ${ }^{41}$, Sarju G Mehta ${ }^{42}$, Imke Metz ${ }^{43}$, Edoardo Monfrini22,23, Daniela Neumann ${ }^{44}$, Michael Noetzel16,45, Mary O'Driscoll ${ }^{46}$, Katrin Õunap ${ }^{47,48}$, Axel Panzer ${ }^{49}$, Sumit Parikh ${ }^{50}$, Prab Prabhakar $^{51}$, Francis Ramond ${ }^{52}$, Richard Sandford ${ }^{53}$, Russell Saneto ${ }^{54,55}$, Calvin Soh ${ }^{56}$, Chloe A Stutterd ${ }^{57}$, Gopinath M Subramanian ${ }^{58}$, Kevin Talbot ${ }^{59}$, Rhys H Thomas $^{60}$, Camilo Toro ${ }^{61}$, Renaud Touraine ${ }^{54}$, Emma Wakeling ${ }^{62}$, Evangeline Wassmer ${ }^{63}$, Andrea Whitney ${ }^{64}$, John H Livingston $^{65}$, Raymond T O'Keefe ${ }^{3}$, Andrew P Badrock ${ }^{1}$

${ }^{1}$ Centre for Genomic and Experimental Medicine, MRC Institute of Genetics and Molecular Medicine, University of Edinburgh, Edinburgh, UK

${ }^{2}$ Laboratory of Neurogenetics and Neuroinflammation, Institut Imagine, Université de Paris, Paris, France

${ }^{3}$ Division of Evolution and Genomic Sciences, Faculty of Biology, Medicine and Health, School of Biological Sciences, Manchester Academic Health Science Centre, University of Manchester, Manchester, UK

${ }^{4}$ Johns Hopkins University School of Medicine, Baltimore, Maryland, USA

${ }^{5}$ Department of Clinical and Experimental Medicine, University of Pisa, Pisa, Italy

${ }^{6}$ IRCCS Fondazione Stella Maris, Pisa, Italy

${ }^{7}$ Department of Neuropediatrics, Kliniken Nordoberpfalz AG, Klinikum Weiden, Germany

8 Oxford Centre for Genomic Medicine, Oxford University Hospitals NHS Foundation Trust, Oxford, UK

${ }^{9}$ Paediatric Neurosurgery Department, Necker-Enfants Malades Hospital, APHP, Université de Paris, Paris, France

${ }^{10}$ Department of Pediatrics, University of Alberta, Edmonton, Alberta, Canada

${ }^{11}$ Paediatric Radiology Department, Hôpital Necker Enfants Malades, AP-HP, University de

Paris, INSERM U1163, Institut Imagine, Paris France

12 Department of Neuropediatrics, Sozialpädiatrisches Zentrum am EVK Düsseldorf, Düsseldorf, Germany

13 HNEkidsRehab, Newcastle, NSW, Australia

14 Neurosciences Department, Queensland Children's Hospital, Brisbane, Queensland, Australia

${ }^{15}$ Clinique de Génétique Guy Fontaine, CHU Lille, F-59000, Lille, France

${ }^{16}$ Department of Neurology, Washington University School of Medicine, St. Louis, MO, USA

This is the author manuscript accepted for publication and has undergone full peer review but has not been through the copyediting, typesetting, pagination and proofreading process, which may lead to differences between this version and the Version of Record. Please cite this article as doi: 10.1002/ajmg.a.61907

This article is protected by copyright. All rights reserved. 
17 Child Neurology and Psychiatry Unit, Department of Medical and Surgical Sciences (DIMEC), S. Orsola Hospital, University of Bologna, Italy

${ }^{18}$ Department of Neurology, Vestfold Hospital, Tønsberg, Norway

${ }^{19}$ Department of Paediatric Neurology, Université de Paris, Hôpital Necker Enfants Malades, Assistance Publique-Hôpitaux de Paris, Paris, France

${ }^{20}$ Department of Paediatric Neurology, University Hospitals Leuven, Leuven, Belgium

${ }^{21}$ Department of Development and Regeneration, KU Leuven, Leuven, Belgium

${ }^{22}$ Foundation IRCCS Ca 'Granda Ospedale Maggiore Policlinico, Neurology Unit, Milan, Italy

23 Dino Ferrari Center, Neuroscience Section, Department of Pathophysiology and Transplantation, University of Milan, Milan, Italy

${ }^{24}$ Division of Medical Genetics, Dalhousie University, Halifax, Nova Scotia, Canada

${ }^{25}$ South West Thames Regional Genetics Service, St George's, University of London, UK

${ }^{26}$ CHRU Nancy, Nancy France

${ }^{27}$ Department of Paediatric Neurology, University Hospital of Wales, Cardiff, UK

${ }_{28}$ Molecular and Clinical Sciences Institute, St. George's University of London, Cranmer Terrace, London, UK

${ }^{29}$ Innovative Medical Research Center, Mashhad Branch, Islamic Azad University, Mashhad, Iran

${ }^{30}$ Hunter Genetics, Hunter New England Local Health District, Waratah, Australia

${ }^{31}$ School of Medicine and Public Health, University of Newcastle, Callaghan, Australia

${ }^{32}$ Department of Medical Genetics, Telemark Hospital Trust, Skien, Norway

33 Department of Paediatric Neurology, Central Manchester University Hospitals NHS Foundation Trust, Manchester, UK

34 The Walton Centre NHS Trust, Lower Lane, Liverpool, UK

${ }^{35}$ Cleveland Clinic Abu Dhabi, United Arab Emirates

${ }^{36}$ Clinical Genetic Service, Manchester Centre for Genomic Medicine, Saint Mary's Hospital, Manchester University Hospitals NHS Foundation Trust, Manchester, UK

${ }^{37}$ Department of Paediatric Neurology, Alder Hey Children's NHS Foundation Trust, Liverpool, UK

${ }^{38}$ Department of Neurology Royal Children's Hospital and Murdoch Children's Research Institute, Melbourne, Australia

39 University of Melbourne Department of Paediatrics, Melbourne, Australia

40 Maritime Medical Genetics, IWK Health Centre, Halifax, Nova Scotia, Canada

41 Department of Neuromuscular Disorders, University College London Queen Square Institute of Neurology, London, UK

${ }^{42}$ East Anglian Regional Genetics Service, Addenbrookes Hospital, Cambridge, UK

43 Department of Neuropathology, University Medical Center, Georg August University, Göttingen, Germany

${ }^{44}$ Klinikum Wilhelmshaven, Department of Neuropediatrics, Germany

45 Department of Pediatrics, Washington University School of Medicine, St. Louis, USA

46 West Midlands Regional Clinical Genetics Service, Birmingham Health Partners, Birmingham Women's Hospital NHS Foundation Trust, Birmingham, UK

${ }^{47}$ Department of Clinical Genetics, Institute of Clinical Medicine, University of Tartu, Tartu, Estonia

48 Department of Clinical Genetics, United Laboratories, Tartu University Hospital, Tartu, Estonia

${ }^{49}$ Paediatric Neurology, DRK Kliniken Berlin-Westend, Berlin, Germany 
${ }^{50}$ Neurogenetics Program, Center for Pediatric Neurology, Neurosciences Institute, Cleveland Clinic, Cleveland, OH, USA

${ }^{51}$ Department of Paediatric Neurology, Great Ormond Street Hospital for Children NHS Foundation Trust, London, UK

52 Service de Génétique, CHU-Hôpital Nord, Saint Etienne, France

53 Academic Department of Medical Genetics, University of Cambridge School of Clinical Medicine, UK

${ }^{54}$ Neuroscience Institute, Division of Paediatric Neurology, Seattle Children's Hospital and University of Washington, Seattle, USA

${ }^{55}$ Department of Neurology, Seattle Children's Hospital and University of Washington, Seattle, USA

${ }^{56}$ Radiology Department, Manchester University Foundation NHS Trust, Manchester, UK

57 Victorian Clinical Genetics Service, Parkville, Australia

58 John Hunter Children's Hospital, New South Wales, Australia

59 Nuffield Department of Clinical Neurosciences, Oxford University, Oxford, UK

60 Translational and Clinical Research Institute, Newcastle University, UK

${ }^{61} \mathrm{NIH}$ Undiagnosed Diseases Program (UDP), National Human Genome Research Institute, National Institutes of Health, Bethesda, USA

${ }^{62}$ North East Thames Regional Genetics Service, Great Ormond Street Hospital for Children NHS Foundation Trust, London, UK

${ }^{63}$ Department of Paediatric Neurology, Birmingham Children's Hospital, Birmingham, UK

64 University Hospital Southampton NHS Foundation Trust, Department of Paediatric Neurology, Southampton, UK

65 Department of Paediatric Neurology, Leeds General Infirmary, Leeds, UK

\section{Corresponding author}

Professor Yanick crow

Centre for Genomic and Experimental Medicine, MRC Institute of Genetics and Molecular Medicine, Crewe Road South, Edinburgh, EH4 2XU, UK

Email: yanickcrow@mac.com

\section{Funding}

The study was supported by a grant to Y.J.C. and R.T.O'K. from the Great Ormond Street Hospital Charity (V4017). Y.J.C. also acknowledges a state subsidy managed by the National Research Agency (France) under the 'Investments for the Future' program bearing the reference ANR-10-IAHU-01 and the MSDAvenir fund (DEVO-DECODE Project). The University of Cambridge has received salary support in respect of Richard Sandford from the NHS in the East of England through the Clinical Academic Reserve. In this regard, the views expressed are those of the authors and not necessarily those of the NHS or Department of Health. K.Õ. is supported by an Estonian Research Council grant (PRG471).

\section{ABSTRACT}

Biallelic mutations in SNORD118, encoding the small nucleolar RNA U8, cause leukoencephalopathy with calcifications and cysts (LCC). Given the difficulty in interpreting the functional consequences of variants in non-protein encoding genes, and the high allelic

This article is protected by copyright. All rights reserved. 
polymorphism across SNORD118 in controls, we set out to provide a description of the molecular pathology and clinical spectrum observed in a cohort of patients with LCC. We identified 64 affected individuals from 56 families. Age at presentation varied from three weeks to 67 years, with disease onset after age 40 years in eight patients. Ten patients had died. We recorded 44 distinct, likely pathogenic, variants in SNORD118. Fifty two of 56 probands were compound heterozygotes, with parental consanguinity reported in only three families. Forty nine of 56 probands were either heterozygous (46) or homozygous (three) for a mutation involving one of seven nucleotides that facilitate a novel intramolecular interaction between the 5' end and 3' extension of precursor-U8. There was no obvious genotype-phenotype correlation to explain the marked variability in age at onset. Complementing recently published functional analyses in a zebrafish model, these data suggest that LCC most often occurs due to combinatorial severe and milder mutations, with the latter mostly affecting 3 ' end processing of precursor-U8.

\section{KEY WORDS}

Leukoencephalopathy with calcifications and cysts

Labrune syndrome

SNORD118

C/D box snoRNA U8

Ribosomopathy

Coats plus

\section{SHORT TITLE}

\section{LCC: genetic and phenotypic spectrum}

\section{INTRODUCTION}

Leukoencephalopathy with calcifications and cysts (LCC), also referred to as Labrune syndrome, is an exclusively neurological Mendelian microangiopathy, where cerebral small blood vessels demonstrate angiomatous-like features, Rosenthal fibre deposition, mineralization and minimal inflammation (Labrune et al., 1996). LCC is characterized by a neuro-radiological triad of (frequently asymmetric) white matter disease, characteristic intracranial calcifications and brain cysts (Livingston et al., 2014). An absence of cerebral atrophy is also a useful radiological discriminator (Livingston et al., 2014). The disease can present at any age from early infancy to late adulthood, and is associated with significant morbidity and early mortality.

In 2016, biallelic mutations in SNORD118, encoding the box C/D small nucleolar RNA (snoRNA) U8, were discovered as the cause of LCC (Jenkinson et al. 2016). Despite being a rare autosomal recessive disorder, 31 of 33 probands were compound heterozygous for two different SNORD118 variants; that is, there was no enrichment for consanguinity and mutational homozygosity. These data suggested that LCC occurs in the context of one severe (null), and one milder (hypomorphic) mutation, with biallelic null mutations likely embryonic lethal. U8 plays a central role in ribosomal biology, ribosomes representing an integral component of the cellular translational machinery (Lafontaine 2015). However, the link 
between a (predicted global) disturbance of ribosomal function and the highly stereotyped features of LCC remains unclear.

It is not possible to use standard in silico algorithms and/or infer damaging status, such as by recognizing a genetic variant as null, in the assessment of the pathogenicity of sequence changes in non-protein encoding genes. Difficulty in determining the functional significance of variants in SNORD118 is further compounded by the high degree of allelic polymorphism observed across the gene in control cohorts. The development of a vertebrate U8 mutant animal model of LCC has allowed an assessment of LCC-associated U8 variants, confirming the importance of combinatorial null and partially functional mutant alleles in disease pathogenesis (Badrock et al., 2020). Of particular note, this work has highlighted a novel intramolecular interaction, involving the $5^{\prime}$ end of SNORD118 and its $3^{\prime}$ extension, necessary for the processing of human precursor U8 (pre-U8), thereby informing on the hypomorphic nature of a series of recurrent mutations observed in LCC.

Here we provide genetic and clinical data relating to the largest cohort of patients with LCC yet published, thereby allowing better definition of the associated molecular pathology and phenotypic spectrum of the disease.

\section{MATERIALS AND METHODS}

\section{Editorial Policies and Ethical Considerations}

The study was approved by the Leeds (East) Research Ethics Committee (10/H1307/132) and the Comité de Protection des Personnes (ID-RCB/EUDRACT: 2014-A01017-40).

\section{Subjects}

Patients were ascertained through direct contact with the Crow group, and via collaborating physicians. Every individual demonstrated two or more of the classical neuro-radiological features of LCC i.e. white matter disease (leukoencephalopathy), characteristic intracranial calcification and brain cysts in the absence of any extra-neurological involvement, in particular: retinal vasculopathy, gastrointestinal haemorrhage and bone fractures as seen in Coats plus, a neuro-radiological mimic of LCC (Livingston et al., 2014). A complete set of clinical data was not available for all patients.

\section{Mutational analysis}

Mutational analysis was performed using standard Sanger sequencing. Primers were designed to generate a 297 base-pair amplicon around SNORD118 (SNORD118-Forward: CGCGTTATGAACTCACCCTA; SNORD118-Reverse: CAGCAAGGTTATCCCAGTCAG). Mutation description is based on the reference sequence NR_033294.1. Population allele frequencies were accessed from the Genome Aggregation Database (gnomAD) (http://gnomad.broadinstitute.org) using Alamut Visual v.2.15 (SOPHiAGENETICS.COM). Rare alleles were defined as those with a frequency of $<0.005$ on gnomAD. Note that whilst SNORD118 is a 136 nucleotide snoRNA, it is annotated on gnomAD as 134 nucleotides in length i.e. not including an extra nucleotide of transcribed sequence at both the $5^{\prime}$ and 3 ' ends.

This article is protected by copyright. All rights reserved. 
Furthermore, gnomAD designates the 5' region and 3' extension of U8 to lie within the 3' UTR of TMEM107.

\section{RESULTS}

\section{Clinical data}

We collated phenotypic data on 64 individuals with LCC from 56 families (Table 1). This cohort includes an update on 28 of 34 patients alive at the time of our initial gene description in 2016 (Jenkinson et al, 2016), previously collected data relating to the six patients deceased at the time of that report and six patients on whom no further update was available. Additionally, we include previously unpublished data on a further set of 24 patients. There were 31 males and 33 females. The age at manifestation of disease varied from three weeks to 67 years, with 40 and 10 patients presenting between $0-9$ and 10 - 19 years of age respectively (Figure 1a). Fourteen individuals presented at age 19 years or over, with disease onset after the age of 40 years in eight patients. The most common presenting features were seizures (24), motor difficulties (18), global developmental delay (14) and symptoms of raised intracranial pressure (8)(Figure 1b). Two patients were initially considered to have a pilocytic astrocytoma, and three neurocysticercosis (two of whom received treatment with albendazole). There were seven sibling pairs, and one family with three affected siblings. The clinical course amongst siblings appeared to be fairly stereotyped. Sixteen patients underwent one (10 patients) or more (6 patients) neurosurgical procedure(s), either for cyst drainage or diagnostic biopsy. We noted three patients experiencing overt psychotic episodes. Most frequently, patients developed a mixed neurological picture, variably comprising seizures, cognitive impairment, mood disturbance, pyramidal signs, dystonia and ataxia. Except in those individuals presenting with developmental delay, cognition was usually normal until presentation, followed thereafter by slow cognitive decline. The duration of follow-up ranged from less than six months to 33 years, during which time almost all patients experienced definite disease progression. Ten patients had died, with the interval between disease manifestation and death ranging from four to 32 years.

\section{Molecular data}

All 64 patients harboured two rare (allele frequency $<0.005$ in gnomAD) variants in SNORD118 (Table 1; Table S1). In total, we observed 44 likely pathogenic mutations, 11 of which were novel i.e. not annotated in gnomAD. Fifty two of 56 probands were compound heterozygotes, with four homozygote probands, three of whom were born to knowingly consanguineous parents. Of the 24 alleles unique to a single family, 10 were novel (Table 2). There were 20 mutant alleles seen in two or more families (Figure 2). Nine mutant alleles were shared by four or more different sets of families. These mutant alleles were highly enriched in the LCC population compared to the frequencies observed in the gnomAD control cohort; for example, the variants $n .81 \mathrm{G}>\mathrm{A}$ and $\mathrm{n} .131 \mathrm{C}>\mathrm{G}$ were both seen in the heterozygous state in five families, where the gnomAD frequencies were 0.00004 and 0.00001 respectively. Fifty four of 64 patients were either heterozygous (51) or homozygous (three) for a mutation involving one of seven nucleotides in either the $5^{\prime}$ end (n.2T; n.3C; n.8G) or the 3' extension (n. $\left.{ }^{\star} 1 C ; n .{ }^{\star 5 C} ; n .{ }^{*} 9 C ; n .{ }^{*} 10 G\right)$ of the gene.

\section{DISCUSSION}


We present clinical and molecular data relating to a cohort of patients with LCC ascertained over a period of more than 15 years. LCC is a severe disorder, associated with significant neurological morbidity and increased mortality. No effective treatments are currently recognised. A striking feature of our cohort is the very wide range of age at which the disease first manifests, varying from early infancy to the seventh decade of life. We observed more than one affected child in seven families. In the absence of molecular testing of asymptomatic siblings, clinical non-penetrance within families, and/or extremes in age-dependent penetrance, cannot be ruled out. No obvious genotype-phenotype correlation could be ascertained to explain the marked variability in age at onset, or the observed differences in disease expression. For example, mutation-identical (n.58A $>\mathrm{G} / \mathrm{n} .{ }^{*} 9 \mathrm{C}>\mathrm{T}$ ) unrelated probands F691 and F2816 presented at the ages of 10 months and 48 years respectively. Similarly, although sharing the genotype n. $20 \mathrm{C}>\mathrm{T} / \mathrm{n} .{ }^{*} 5 \mathrm{C}>\mathrm{G}, \mathrm{F} 433$ presented at age 50 years, whilst all three siblings in F362 had manifest disease by age 2 years. A further example is described by Iwama et al., who reported two individuals, both compound heterozygous for the n.39G $>C$ and n.72A>G mutations, presenting at age 1 month and age 45 years (Iwama et al. 2017). These data suggest the importance of additive genetic factors and/or environmental triggers in determining disease status.

In our well phenotyped cohort, all probands harboured biallelic rare variants in SNORD118. Indeed, we have yet to identify a patient with classical features of LCC in the absence of such mutations, suggesting that the disease is genetically homogeneous. In the case of SNORD118, the difficulty in assessing the functional significance of variants in a non-protein encoding gene is compounded by a high degree of allelic polymorphism observed in controls. However, our molecular data, including the observation of novel and rare allele sharing across multiple pedigrees, the low frequency of biallelic rare SNORD118 variants in controls (Jenkinson et al. 2016), and the results of in vitro (Jenkinson et al. 2016) and in vivo (Badrock et al. 2020) functional analyses, together provide compelling evidence that mutations in SNORD118 cause LCC.

As noted previously, given that most rare autosomal recessive traits are enriched for individuals born to consanguineous parents, the low frequency of allelic homozygosity seen in our series suggests that biallelic null mutations in SNORD118 are incompatible with development. In keeping with this hypothesis, the U8-3 zebrafish null mutant is embryonic lethal (Badrock et al., 2020). In contrast, homozygosity for (most) hypomorphic variants in SNORD118 presumably does not result in disease, or is associated with a phenotype not ascertained by us. The prediction from these data is that LCC most frequently results from the combination of one severe (null), and one milder (hypomorphic) mutation, data again supported by in vivo experiments (Badrock et al., 2020). These molecular insights explain the presence in control databases of a small number of homozygotes for five of the 44 putative causal mutations that we report. Of note, these alleles are distinct from those three putative mutations seen in the homozygous state in four unrelated patients from our series, two of which fall in the $5^{\prime}$ end (n.8C>G; seen in two separate individuals) or $3^{\prime}$ extension (n. ${ }^{*} \mathrm{C}>\mathrm{G}$ ) of pre-U8. We predict that homozygosity for such hypomorphic mutant alleles result in a loss of U7 activity to a level which is compatible with initially normal development, but insufficient to maintain cellular homeostasis long-term. All told, an understanding of these aspects of the molecular pathology of LCC is of particular relevance for the correct interpretation of diagnostic testing results. 
Nine of the mutations described here have been previously demonstrated to confer a functional defect in vitro (Jenkinson et al. 2016). For example, the n.-54_-49del variant was associated with a profound reduction in transcriptional activity relative to wild-type sequence, and four variants (n.57G >A, n.58A>G, n.61A>G and n.60_61insT) observed in the U8 box C region all demonstrated reduced binding of $15.5 \mathrm{~K}$ protein. Of particular note, four mutations (n. $\left.{ }^{\star} 1 C ; n .{ }^{*} 5 C ; n .{ }^{*} 9 C ; n .{ }^{*} 10 G\right)$ in the region immediately downstream of the mature U8 sequence, result in abnormal in vitro processing of pre-U8. More recently, we have shown that mutations in three nucleotides (n.2T; n.3C; n.8G) at the $5^{\prime}$ end of pre-U8 also alter processing of the $3^{\prime}$ extension, thereby identifying a previously unappreciated Watson-Crick base-pairing between the 5' end and 3' extension of human pre-U8 (Badrock et al., 2020). Indeed, 54 of 64 patients in our cohort were heterozygous for a mutation involving one of these seven nucleotides, an enrichment seen in other molecularly-proven cases of LCC published to date (eight of 17 patients with recorded biallelic mutations)(Iwama et al., 2017; Iwasaki et al., 2017; Jin et al., 2018; Taglia et al., 2018; Pessoa 2018; Hermens et al., 2018; Osman et al., 2020)(Table S2). Recognition that these $5^{\prime}$ end and $3^{\prime}$ extension variants represent hypomorphic alleles suggests the possibility to modify their expression, or their effect on preU8 processing, as a therapeutic strategy relevant to the majority of patients with LCC.

The box C/D snoRNA U8 plays a central role in ribosome biogenesis. Alterations in ribosomal components underlie a heterogeneous class of diseases referred to as the ribosomopathies, with a diversity in associated clinical phenotype providing an indication of the multiple specialized roles of the ribosome in normal physiology (Farley-Barnes et al., 2019). Despite ubiquitous expression of U8, germline mutations in SNORD118 cause LCC, a progressive microangiopathy apparently limited to the cerebral vasculature. Of note, although the radiological phenotype of the exclusively neurological disease LCC is highly distinctive, it is not pathognomonic, as remarkably similar neuro-imaging is seen in the multisystem disorder Coats plus, caused by mutations in proteins involved in telomere maintenance (Anderson et al., 2012; Polvi et al., 2012; Simon et al., 2016; Takai et al., 2016). The precise link between U8 and cerebral vascular homeostasis awaits elucidation, and may conceivably involve both defects in ribosomal processing and potentially undefined non-ribosomal functions of U8.

\section{Acknowledgements}

We sincerely thank all of the patients, their families and collaborating physicians who provided help in compiling the information included in this manuscript. The study was supported by a grant to Y.J.C. and R.T.O'K. from the Great Ormond Street Hospital Charity (V4017). Y.J.C. also acknowledges a state subsidy managed by the National Research Agency (France) under the 'Investments for the Future' program bearing the reference ANR-10-IAHU-01 and the MSDAvenir fund (DEVO-DECODE Project). The University of Cambridge has received salary support in respect of Richard Sandford from the NHS in the East of England through the Clinical Academic Reserve. In this regard, the views expressed are those of the authors and not necessarily those of the NHS or Department of Health. KÕ is supported by an Estonian Research Council grant (PRG471).

\section{Conflicts of interests}

None of the authors report any conflicts of interest. 


\section{Author contributions}

Y.J.C., H.M., G.I.R., L.S., E.M.J., J.H., R.T.O. and A.B. generated and analysed data. K.B., R.B., A.B., E.B., T.B., F.B., N.B., J.B., H.B., S.C., R.C., A.C-H.N., F.C., D.B.C., D.M.C., A.dB., N.D., I.D., L.dW., A.DF., S.R.D., S.D., F.E., M.F., G.F., E.G.K., J.G., F.G., H.G., H.T.H., I.H., A.J., E.A.J., R.K., R.J.L., S.M., R.M., S.G.M., I.M., E.M., D.N., M.N., M.O'D., K.O., A.P., S.P., P.P., F.R., R.Sand., R.San., C.S., C.A.S., G.M.S., K.T., R.H.T., C.T., R.T., E.Wak., E.Was., and A.W. ascertained and diagnosed patients and supplied clinical and laboratory data. Y.J.C. was responsible for the design of the study and wrote the manuscript which was reviewed by all authors.

Data sharing: Mutation data have been submitted to CLINVAR (SCV001364098 SCV001364141).

\section{References}

Anderson, B.H., Kasher, P.R., Mayer, J., Szynkiewicz, M., Jenkinson, E.M., Bhaskar, S.S., ... Crow, Y.J. (2012). Mutations in CTC1, encoding conserved telomere maintenance component 1, cause Coats plus. Nature Genetics, 44(3), 338-342.

Badrock, A.P., Uggenti, C., Wacheul, W., Crilly, S., Jenkinson, E.M. Rice, G.I., ... O'Keefe, R.T. (2020). Analysis of U8 snoRNA variants in zebrafish reveals how bi-allelic variants cause leukoencephalopathy with calcifications and cysts. American Journal of Human Genetics. 106(5), 694-706.

Farley-Barnes, K.I., Ogawa, L.M., Baserga, S.J. (2019). Ribosomopathies: Old concepts, New Controversies. Trends in Genetics, 35(10), 754-767.

Hermens, M., van der Knaap, M.S., Kamsteeg, E.J., Willemsen, M.A. (2018). A brother and sister with intellectual disability and characteristic neuroimaging findings. European Journal of Paediatric Neurology, 22(5), 866-869.

Iwama, K., Mizuguchi, T., Takanashi, J.I., Shibayama, H., Shichiji, M., Ito, S., ... Matsumoto, N. (2017). Indentification of novel SNORD118 mutations in seven patients with leukoencephalopathy with brain calcifications and cysts. Clinical Genetics, 92(2), 180-187.

Iwasaki, Y., Hoshino, K.I., Mori, K., Ito, M., Kawai, Y., Mimuro, M., ... Yoshida, M. (2017). Longitudinal clinical and neuro-radiological findings in a patient with leukoencephalopathy with brain calcifications and cysts (Labrune syndrome). eNeurologicalSci, 8, 28-30.

Jenkinson, E.M., Rodero, M.P., Kasher, P.R., Uggenti, C., Oojageer, A., Goosey, L.C., ... Crow, Y.J. (2016). Mutations in SNORD118 cause the cerebral microangiopathy leukoencephalopathy with calcifications and cysts. Nature Genetics, 48(10), 1185-1192.

Jin, H., Wu, H.S., Ding, C.H., Jin, Z., Zhou, C.J., Zhang, W.H., ... Fang, F. (2018). Clinical features and diagnosis of childhood leukoencephalopathy with cerebral calcifications and cysts in four cases. Zhongua Er Ke Za Zhi, 56(7), 539-544.

This article is protected by copyright. All rights reserved. 
Labrune, P., Lacroix, C., Goutières, F., de Laveaucoupet, J., Chevalier, P., Zerah, M., ... Landrieu, P. (1996). Extensive brain calcifications, leukodystrophy, and formation of parenchymal cysts: a new progressive disorder due to diffuse cerebral microangiopathy. Neurology, 46(5), 1297-1301.

Lafontaine, D. (2015). Noncoding RNAs in eukaryotic ribosome biogenesis and function. Nature Structural Molecular Biology, 22(1),11-19.

Livingston, J.H., Mayer, I., Jenkinson, E., Kasher, P., Stivaros, S., Berger, A., ... Crow, Y.J. (2014). Leukoencephalopathy with calcifications and cysts: a purely neurological disorder distinct from coats plus. Neuropediatrics, 45(3),175-182.

Osman, O., Labrune, P., Reiner, P., Sarov, M., Nasser G., Riant, F., ... Denier, C. (2020). leukoencephalopathy with calcifications and cysts (LCC): 5 cases and literature review. Revue Neurologique, 176(3), 170-179.

Pessoa, A. (2018). Blood-brain barrier permeability in a patient with Labrune syndrome due to SNORD118 mutations: would this be the mechanism for progressive worsening? European Journal of Neurology, 25(8), e88-e90.

Polvi, A., Linnankivi, T., Herva, R., Keating, J.P., Mäkitie, O., Pareyson, D., ... Lehesjoki, A.E. (2012). Mutations in CTC1, encoding the CTS telomere maintenance complex component 1 , cause cerebroretinal microangiopathy with calcifications and cysts. American Journal of Human Genetics, 90(3), 540-549.

Simon, A.J., Lev, A., Zhang, Y., Weiss, B., Rylova, A., Eyal, E., ... Somech, R. (2016). Mutations in STN1 cause Coats plus syndrome and are associated with genomic and telomere defects. Journal of Experimental Medicine, 213(8), 1429-1440.

Taglia, I., Di Donato, I., De Stefano, N., Bianchi, S., Galluzzi, P., Federico, A., Dotti, M.T. (2018). Blood-brain barrier permeability in a patient with Labrune syndrome due to SNORD118 mutations. European Journal of Neurology, 25(8):e86-e87.

Takai, H., Jenkinson, E., Kabir, S., Babul-Hirji, R., Najm-Tehrani, N., Chitayat, D.A., Crow, Y.J., de Lange, T. (2016). A POT1 mutation implicates defective telomere end fill-in and telomere truncations in coats plus. Genes and Development, 30(7), 812-826.

Table 1. Sex, age, presenting feature, status $/$ age at last contact, and SNORD118 variants observed in each patient

This article is protected by copyright. All rights reserved. 
A, alive; D, deceased; DD, developmental delay; F, female; M, male; Mo, months; MD, motor disorder; RICP, raised intracranial pressure; $S$, seizures; $Y$, years

$\wedge$ F344 was homozygous for both n.8G $>C$, and n.113C $>$ T. n.8G $>C$ was considered most likely to be the pathogenic mutation given that is seen in other families.

$\wedge$ F819: Both children inherited a paternal deletion, but different maternally inherited missense mutation. The asymptomatic mother is compound heterozygous for $n .{ }^{*} 1 \mathrm{C}>\mathrm{T}$ and n. ${ }^{*} 9 \mathrm{C}>\mathrm{T}$.

$\wedge \wedge$ F2089 also carried a n.119G $>T$ in combination with $n .{ }^{*} 9 \mathrm{C}>\mathrm{T}$ and $\mathrm{n} .81 \mathrm{G}>\mathrm{A}$. The latter two are thought likely to be the pathogenic mutations given that they are seen in other families. Parental DNA was not available to test phase.

\section{Table 2. List of SNORD118 variants identified by patient(s) with LCC.}

Genomic coordinates of variants identified and their frequency on gnomAD are given. Families in this study in which these variants are listed. Note is also made of variants and families identified in mutation-positive cases published by other groups (with the numbers of probands in these papers given in brackets.

† All genomic coordinates should be preceded by Chr17(GRCh37):

$\wedge$ SNORD118 NR_033294.1

Hom = homozygous; Het = heterozygous; gnomAD = Genome Aggregation Database

* Number of homozygote alleles recorded in gnomAD for each variant

** Number of heterozygote alleles recorded in gnomAD for each variant

₹ Number in brackets is the number of homozygote alleles recorded in the population with the highest frequency on gnomAD

$\S$ Deletion extends beyond these boundaries, but boundaries have not been fully defined Note: F344 was homozygous for both $n .8 \mathrm{G}>\mathrm{C}$, and $\mathrm{n} .113 \mathrm{C}>\mathrm{T}$. $\mathrm{n} .8 \mathrm{G}>\mathrm{C}$ was considered most likely to be the pathogenic mutation given that is seen in other families.

Note: F2089 also carried a $n .119 G>T$ in combination with $n .{ }^{*} 9 \mathrm{C}>\mathrm{T}$ and $\mathrm{n} .81 \mathrm{G}>\mathrm{A}$. The latter two are thought likely to be the pathogenic mutations given that they are seen in other families. Parental DNA was not available to test phase. 


\section{Figure legends}

Figure 1. (a) Number of patients by age at presentation ( $\mathrm{Y}$, years). (b) Presenting features in the cohort of 64 SNORD118 mutation positive patients

S, seizures; MD, motor difficulties; DD, developmental delay; RICP, raised intracranial pressure.

Figure 2. A schematic of SNORD118 demonstrating the putative mutations seen in the current study

Numbers in brackets indicate the number of families in which a specific mutant allele has been seen. Mutations above the gene are those in which a substitution has been observed at a particular allele in more than one family. Mutations below the gene are those in which a substitution was observed in a single family in our cohort. Mutations in green indicate (seven) residues at the $5^{\prime}$ end and $3^{\prime}$ extension of U8 that are, predicted to interact and are associated with impaired pre-U8 processing. The orange boxes highlight the distal (DSE) and proximal (PSE) sequence elements. From 5' to 3': box C, the LSm-binding site and box D in SNORD118 (red boxes); processed 3' extension (blue line); $3^{\prime}$ box at the end of the precursor transcript (violet box).

This article is protected by copyright. All rights reserved. 
(a)

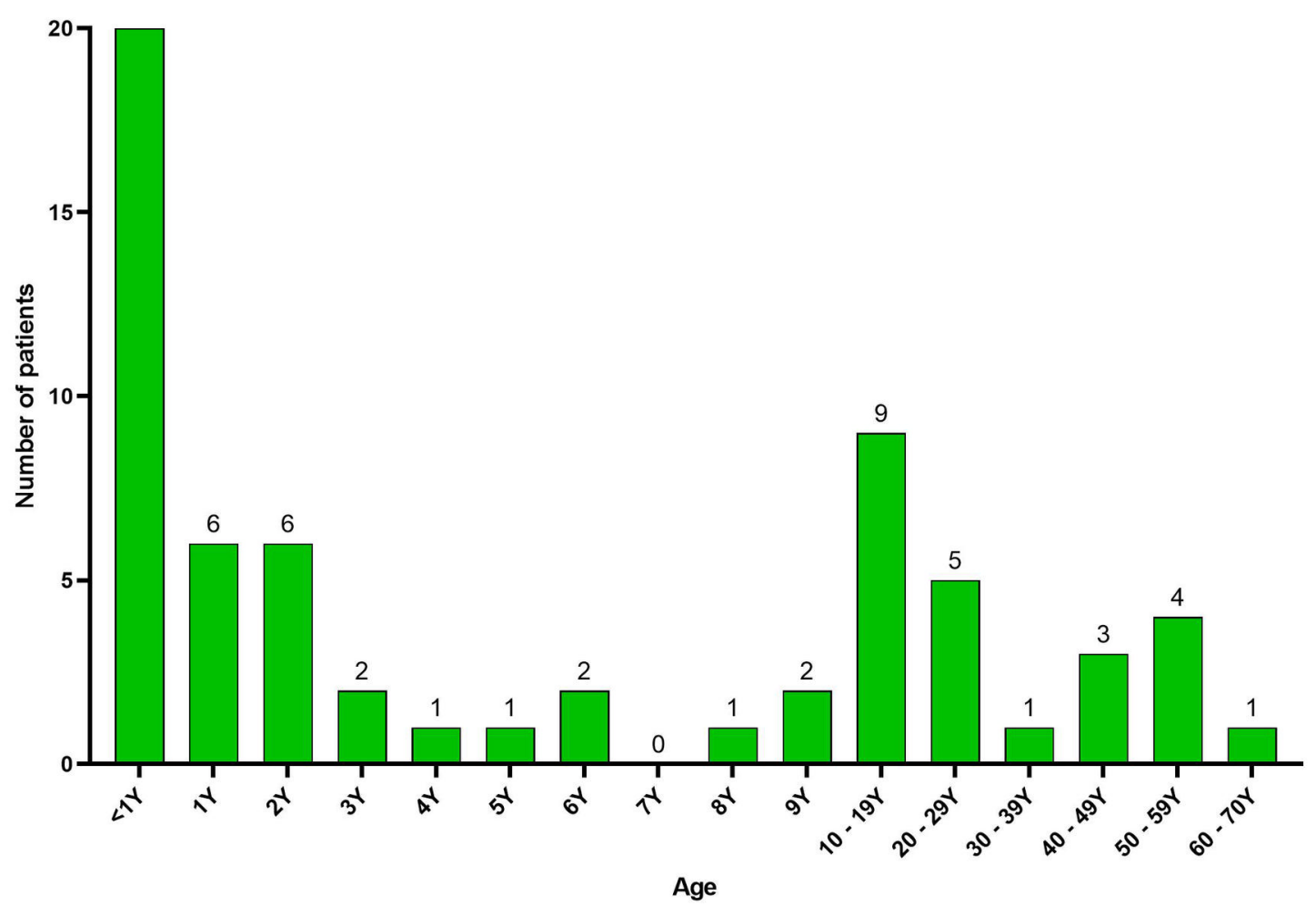

(b)

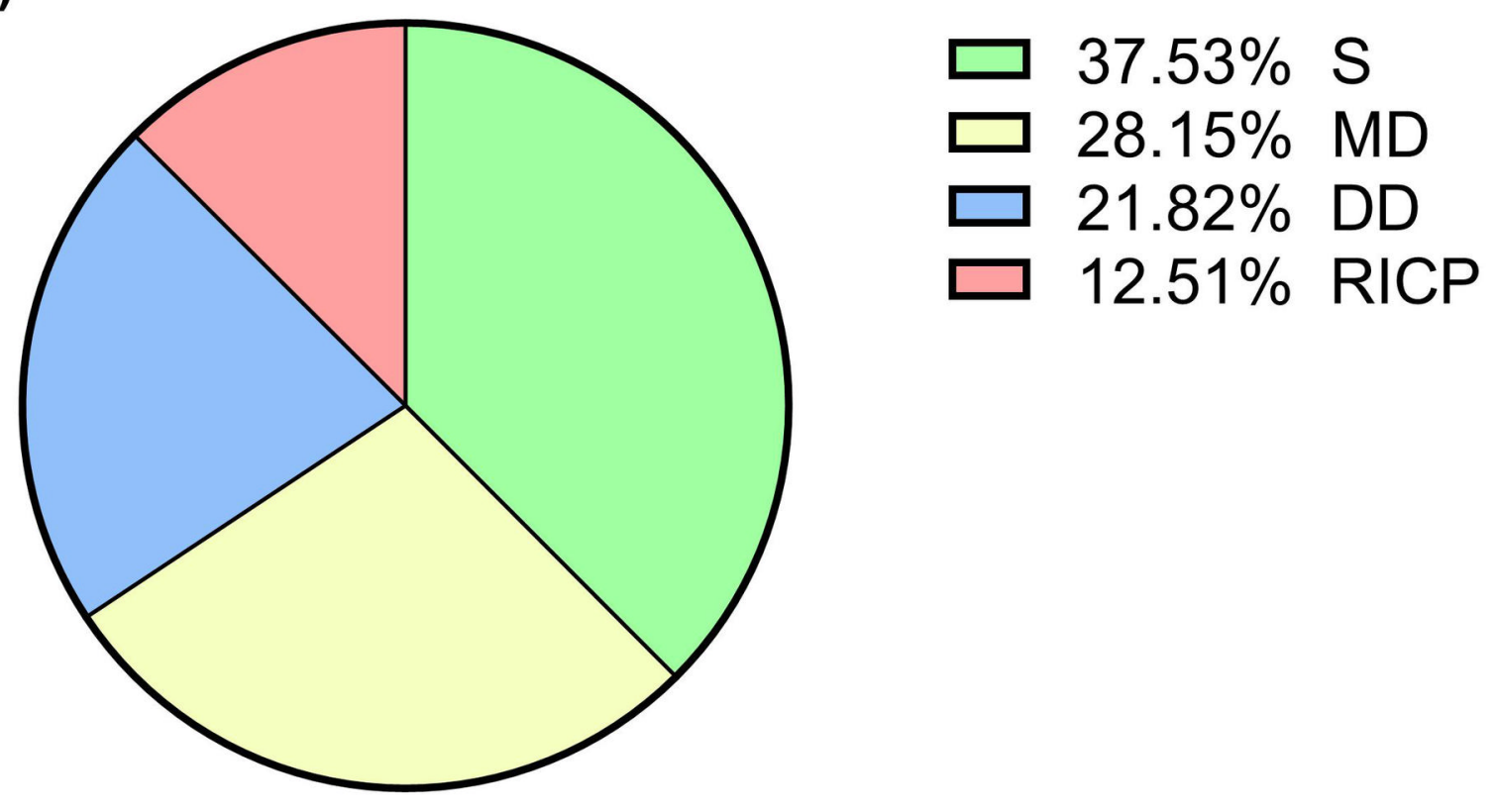

AJMGA_61907_Figure 1.tiff 


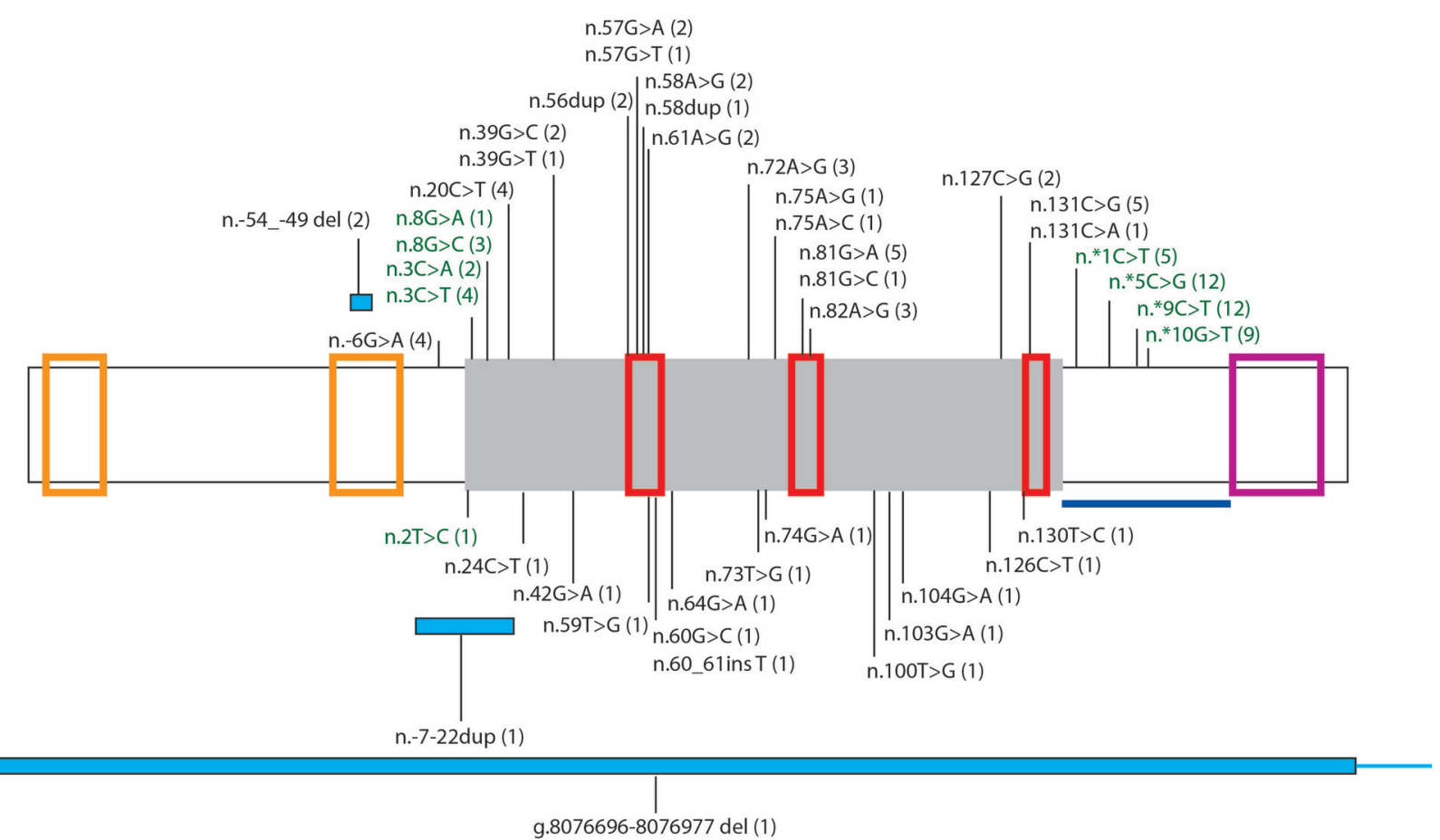

AJMGA_61907_Figure 2.tiff

This article is protected by copyright. All rights reserved. 


\begin{tabular}{|c|c|c|c|c|c|c|}
\hline Patient & Sex & $\begin{array}{c}\text { Age at } \\
\text { presentation }\end{array}$ & $\begin{array}{l}\text { Presenting } \\
\text { feature }\end{array}$ & $\begin{array}{l}\text { Status } \\
\text { at last } \\
\text { contact }\end{array}$ & $\begin{array}{c}\text { Age at last } \\
\text { contact/death }\end{array}$ & SNORD118 variants \\
\hline F172 & $\mathrm{M}$ & $8 w k s$ & $\mathrm{~s}$ & $\mathrm{~A}$ & $19 Y$ & n.56dup / n.*10G>T \\
\hline F278 & $M$ & $1 Y$ & $S$ & $\mathrm{D}$ & $16 Y$ & n.8G>C / n.75A>G \\
\hline F281 & $M$ & $4 Y$ & $\mathrm{MD}$ & $A$ & $15 Y$ & n. $3 \mathrm{C}>\mathrm{T} / \mathrm{n} .81 \mathrm{G}>\mathrm{C}$ \\
\hline F285 & $\mathrm{M}$ & $12 \mathrm{Y}$ & $\mathrm{S}$ & D & $32 Y$ & n. $57 \mathrm{G}>\mathrm{A} / \mathrm{n} .{ }^{*} 5 \mathrm{C}>\mathrm{G}$ \\
\hline F309 & $\mathrm{F}$ & $2 Y$ & DD & A & $26 Y$ & n. $3 \mathrm{C}>\mathrm{T} / \mathrm{n} .131 \mathrm{C}>\mathrm{G}$ \\
\hline F330 & $\mathrm{M}$ & $3 Y$ & MD & A & $22 Y$ & n. $8 \mathrm{G}>\mathrm{A} / \mathrm{n} .82 \mathrm{~A}>\mathrm{G}$ \\
\hline F331.1 & $\mathrm{F}$ & $2 Y$ & MD & $A$ & $25 Y$ & n.72A>G / n.*10G>T \\
\hline F331.2 & $\mathrm{F}$ & $5 \mathrm{Mo}$ & $\mathrm{S}$ & $\mathrm{D}$ & $15 Y$ & n.72A>G / n. $* 10 G>T$ \\
\hline F334 & $\mathrm{F}$ & $6 Y$ & DD & A & $30 Y$ & $\mathrm{n} .82 \mathrm{~A}>\mathrm{G} / \mathrm{n} . * 10 \mathrm{G}>\mathrm{T}$ \\
\hline F337 & $\mathrm{M}$ & $18 \mathrm{Mo}$ & $\mathrm{s}$ & A & $25 \mathrm{Y}$ & n.2T>C/n.58dup \\
\hline F343 & $\mathrm{M}$ & $9 \mathrm{Y}$ & $\mathrm{MD}$ & A & $38 Y$ & n.-7_22dup / n. ${ }^{*}$ C $>\mathrm{G}$ \\
\hline F344 & $M$ & $7 \mathrm{Wk}$ & $\mathrm{S}$ & A & $14 Y$ & n.8G>C homozygous ${ }^{\wedge}$ \\
\hline F362.1 & $\mathrm{F}$ & $2 Y$ & $\mathrm{~S}$ & A & $15 Y$ & n. $20 \mathrm{C}>\mathrm{T} / \mathrm{n} \cdot{ }^{*} 5 \mathrm{C}>\mathrm{G}$ \\
\hline F362.2 & $\mathrm{F}$ & $2 Y$ & $\mathrm{DD}$ & A & $13 Y$ & n. $20 \mathrm{C}>\mathrm{T} / \mathrm{n} \cdot{ }^{*} 5 \mathrm{C}>\mathrm{G}$ \\
\hline F362.3 & $\mathrm{M}$ & $2 Y$ & DD & A & $9 Y$ & n. $20 \mathrm{C}>\mathrm{T} / \mathrm{n} \cdot{ }^{* 5 C}>\mathrm{G}$ \\
\hline F414 & $M$ & $25 Y$ & RICP & A & $41 Y$ & n. $61 \mathrm{~A}>\mathrm{G} / \mathrm{n} \cdot{ }^{*} 1 \mathrm{C}>\mathrm{T}$ \\
\hline F426.1 & $M$ & $<6 \mathrm{Mo}$ & $\mathrm{DD}$ & A & $24 Y$ & n. $81 \mathrm{G}>\mathrm{A} / \mathrm{n} . * 5 \mathrm{C}>\mathrm{G}$ \\
\hline F426.2 & $M$ & $<6 \mathrm{Mo}$ & $\mathrm{DD}$ & A & $25 Y$ & n. $81 \mathrm{G}>\mathrm{A} / \mathrm{n} . * 5 \mathrm{C}>\mathrm{G}$ \\
\hline F433 & $M$ & $54 \mathrm{Y}$ & MD & $\mathrm{D}$ & $58 \mathrm{Y}$ & n. $20 \mathrm{C}>\mathrm{T} / \mathrm{n} \cdot{ }^{*} 5 \mathrm{C}>\mathrm{G}$ \\
\hline F445 & $\mathrm{F}$ & $6 \mathrm{Mo}$ & $\mathrm{S}$ & A & $11 Y$ & n.127C $>$ G / n. $* 5 C>G$ \\
\hline F446 & $M$ & $10 \mathrm{Mo}$ & $S$ & $\mathrm{D}$ & $13 Y$ & n. ${ }^{*} 5 \mathrm{C}>\mathrm{G}$ homozygous \\
\hline F454.1 & $\mathrm{F}$ & $14 Y$ & MD & A & $15 Y$ & n.-54_-49del / n. $* 5 C>G$ \\
\hline F454.2 & $\mathrm{F}$ & $11 Y$ & MD & A & $12 Y$ & n.-54_-49del / n. $* 5 C>G$ \\
\hline F465 & $M$ & $15 \mathrm{Mo}$ & $\mathrm{S}$ & A & $13 Y$ & n.60_61insT / n.82A>G \\
\hline F521.1 & $\mathrm{F}$ & $<12 \mathrm{Mo}$ & $\mathrm{DD}$ & A & $18 Y$ & n.104G $>$ A / n.131C>G \\
\hline F521.2 & $M$ & $1 Y$ & $\mathrm{~S}$ & A & $14 Y$ & n.104G $>$ A / n.131C>G \\
\hline F551 & $\mathrm{F}$ & $<1 Y$ & $\mathrm{DD}$ & $\mathrm{D}$ & $28 Y$ & n.127C $>$ G / n. ${ }^{*} 9 \mathrm{C}>\mathrm{T}$ \\
\hline F564 & $M$ & 9Mo & $\mathrm{DD}$ & A & $11 Y$ & n.126C $>T / n . * 1 C>T$ \\
\hline F641 & $M$ & $4 \mathrm{Mo}$ & $\mathrm{DD}$ & A & $10 Y$ & n.61A>G / n.*10G>T \\
\hline F691 & $M$ & $10 \mathrm{Mo}$ & $S$ & A & $9 Y$ & n.58A $>$ G / n. $* 9 C>T$ \\
\hline F730 & $\mathrm{F}$ & $2 \mathrm{Mo}$ & $S$ & A & $11 Y$ & $\mathrm{n} .81 \mathrm{G}>\mathrm{A} / \mathrm{n} . * 10 \mathrm{G}>\mathrm{T}$ \\
\hline F766 & $\mathrm{F}$ & $12 Y$ & MD & A & $16 Y$ & n. $3 \mathrm{C}>\mathrm{A} / \mathrm{n} .42 \mathrm{G}>\mathrm{A}$ \\
\hline F780.1 & $\mathrm{F}$ & $3 \mathrm{Mo}$ & $\mathrm{S}$ & A & $19 Y$ & n.131C $>$ G / n. ${ }^{*} 1 \mathrm{C}>\mathrm{T}$ \\
\hline F780.2 & $\mathrm{F}$ & $6 Y$ & $\mathrm{DD}$ & A & $11 Y$ & n.131C>G / n. ${ }^{*} 1 \mathrm{C}>\mathrm{T}$ \\
\hline F819.1 & $\mathrm{F}$ & $12 \mathrm{Y}$ & $\mathrm{S}$ & $A$ & $37 Y$ & n.-70_n.?*76del / n. ${ }^{*} 1 \mathrm{C}>T^{\wedge \wedge}$ \\
\hline F819.2 & $M$ & $5 Y$ & $\mathrm{DD}$ & $\mathrm{D}$ & $36 Y$ & n.-70_n.?*76del / n. ${ }^{*} 9 \mathrm{C}>\mathrm{T}^{\wedge \wedge}$ \\
\hline F856 & $M$ & $11 Y$ & RICP & A & $21 Y$ & n. $24 \mathrm{C}>\mathrm{T} / \mathrm{n} .{ }^{* 10 G}>\mathrm{T}$ \\
\hline F906 & $\mathrm{M}$ & $1 Y$ & DD & $A$ & $10 Y$ & n.39G >C / n.103G >A \\
\hline F1127 & $\mathrm{M}$ & $<6 \mathrm{Mo}$ & $S$ & $A$ & $7 Y$ & n.100T>G / n. *9C>T \\
\hline F1172 & $\mathrm{F}$ & $50 Y$ & MD & A & $60 Y$ & n.131C $>$ G / n. ${ }^{*} 9 \mathrm{C}>\mathrm{T}$ \\
\hline F1288 & $\mathrm{F}$ & $3 Y$ & $\mathrm{MD}$ & A & $20 Y$ & n.59T>G / n. *9C>T \\
\hline F1424 & $\mathrm{F}$ & $6 \mathrm{Mo}$ & $\mathrm{S}$ & A & $13 Y$ & n. $-6 \mathrm{G}>\mathrm{A} / \mathrm{n} .130 \mathrm{~T}>\mathrm{C}$ \\
\hline F1445 & $\mathrm{F}$ & $8 Y$ & $\mathrm{MD}$ & $\mathrm{D}$ & $12 Y$ & n. $3 \mathrm{C}>\mathrm{T} / \mathrm{n} .81 \mathrm{G}>\mathrm{A}$ \\
\hline F1722 & $\mathrm{F}$ & $42 Y$ & MD & A & $43 Y$ & n. ${ }^{1} 1 \mathrm{C}>\mathrm{T} / \mathrm{n} \cdot{ }^{*} 5 \mathrm{C}>\mathrm{G}$ \\
\hline
\end{tabular}

This article is protected by copyright. All rights reserved. 


\begin{tabular}{|c|c|c|c|c|c|c|}
\hline F1954 & $\mathrm{M}$ & 4Mo & $S$ & $A$ & $15 Y$ & n.39G>T homozygous \\
\hline F1968 & $\mathrm{F}$ & $22 Y$ & MD & $A$ & $26 Y$ & n. $-6 \mathrm{G}>\mathrm{A} / \mathrm{n} .131 \mathrm{C}>\mathrm{G}$ \\
\hline F2036 & $\mathrm{F}$ & $54 Y$ & RICP & $A$ & $59 Y$ & $\mathrm{n} .81 \mathrm{G}>\mathrm{A} / \mathrm{n} \cdot{ }^{*} 10 \mathrm{G}>\mathrm{T}$ \\
\hline F2054 & $\mathrm{M}$ & $<6 \mathrm{Mo}$ & $S$ & A & $5 Y$ & n.20C $>$ T / n. $* 10 G>T$ \\
\hline F2089 & $F$ & $21 Y$ & $S$ & A & $24 Y$ & $\mathrm{n} .81 \mathrm{G}>\mathrm{A} / \mathrm{n} \cdot{ }^{*} 9 \mathrm{C}>\mathrm{T}^{\wedge \wedge \wedge}$ \\
\hline F2143 & $\mathrm{F}$ & $59 Y$ & $M D$ & $A$ & $64 Y$ & n.64G $>$ A / n. $* 9 C>T$ \\
\hline$F 2243$ & $\mathrm{M}$ & $67 Y$ & MD & $\mathrm{D}$ & $76 Y$ & n. $-6 \mathrm{G}>\mathrm{A} / \mathrm{n} .74 \mathrm{G}>\mathrm{A}$ \\
\hline F2380 & $\mathrm{F}$ & $2 \mathrm{Mo}$ & $\mathrm{S}$ & $A$ & $6 Y$ & n. $57 \mathrm{G}>\mathrm{T} / \mathrm{n} . * 5 \mathrm{C}>\mathrm{G}$ \\
\hline$F 2427$ & $\mathrm{~F}$ & $25 Y$ & $S$ & $A$ & $27 Y$ & n. $72 A>G /$ n. $* 9 C>T$ \\
\hline F2474 & $\mathrm{F}$ & $42 Y$ & $\mathrm{~S}$ & $A$ & $50 Y$ & n.73T>G / n. $* 5 C>G$ \\
\hline F2480 & $M$ & $12 Y$ & RICP & $A$ & $14 Y$ & n.72A $>$ G / n. $* 10 G>T$ \\
\hline F2494 & $M$ & $12 Y$ & RICP & $A$ & $16 Y$ & n.3C>T / n.57G >A \\
\hline F2689 & $\mathrm{F}$ & $2 Y$ & MD & A & $35 Y$ & n.39G $>$ C / n.75A $>C$ \\
\hline F2737 & $F$ & $3 \mathrm{Wk}$ & $S$ & $A$ & $14 Y$ & n.56dup / n. $* 5 C>G$ \\
\hline F2816 & $M$ & $48 Y$ & RICP & $A$ & $48 Y$ & n.58A $>$ G $/$ n. ${ }^{*} 9 \mathrm{C}>\mathrm{T}$ \\
\hline F2871 & $\mathrm{F}$ & $9 Y$ & RICP & A & $10 Y$ & n.-54_-49del / n.*9C>T \\
\hline N8058 & $\mathrm{F}$ & $28 Y$ & MD & A & $48 Y$ & n. $-6 G>A / n .131 C>A$ \\
\hline N11301 & $M$ & $15 Y$ & MD & $A$ & $48 Y$ & n. $3 C>A / n .20 C>T$ \\
\hline DIF_1 & $\mathrm{F}$ & $37 Y$ & RICP & $\mathrm{D}$ & $69 Y$ & n.60G $>C /$ n. $* 9 C>T$ \\
\hline Hild_1 & $M$ & $1 Y$ & DD & $A$ & $4 Y$ & n.8G>C homozygous \\
\hline
\end{tabular}

Table 1. Sex, age, presenting feature, status I age at last contact, and SNORD118 variants observed in each patient

A, alive; D, deceased; DD, developmental delay; F, female; M, male; Mo, months; MD, motor disorder; RICP, raised intracranial pressure; $\mathrm{S}$, seizures; $\mathrm{Y}$, years

${ }^{\wedge} \mathrm{F} 344$ was homozygous for both $\mathrm{n} .8 \mathrm{G}>\mathrm{C}$, and $\mathrm{n} .113 \mathrm{C}>\mathrm{T}$. n.8G $>\mathrm{C}$ was considered most likely to be the pathogenic mutation given that is seen in other families.

$\wedge^{\wedge}$ F819: Both children inherited a paternal deletion, but different maternally inherited missense mutation. The asymptomatic mother is compound heterozygous for $n .{ }^{*} 1 \mathrm{C}>T$ and $n .{ }^{*} 9 \mathrm{C}>T$.

$\wedge \wedge$ F2089 also carried a n.119G $>T$ in combination with $n .{ }^{*} 9 \mathrm{C}>\mathrm{T}$ and $\mathrm{n} .81 \mathrm{G}>\mathrm{A}$. The latter two are thought likely to be the pathogenic mutations given that they are seen in other families. Parental DNA was not available to test phase. 


\begin{tabular}{|c|c|c|c|c|c|c|c|c|}
\hline Genomic coordinates $\dagger$ & rs number & $\begin{array}{l}\text { SNORD118 } \\
\text { nomenclature^ }^{\wedge}\end{array}$ & $\begin{array}{l}\text { gnomAD } \\
\text { total allele } \\
\text { count }\end{array}$ & Hom* ${ }^{*}$ & Het $^{\star \star}$ & $\begin{array}{l}\text { Calculated } \\
\text { gnomAD } \\
\text { frequency }\end{array}$ & $\begin{array}{l}\text { Highest population } \\
\text { frequency on } \\
\text { gnomAD } \neq\end{array}$ & $\begin{array}{l}\text { Families harboring each } \\
\text { variant }\end{array}$ \\
\hline g.8076761C>A & rs116395281 & n. ${ }^{* 10 G}>T$ & 262502 & 4 & 655 & 0.002495 & African $0.02080(4)$ & $\begin{array}{l}\text { F172, F331, F334, F641, } \\
\text { F730, F856, F2036, } \\
\text { F2054, F2480, Taglia et al } \\
\text { (2) }\end{array}$ \\
\hline g.8076762G>A & rs201787275 & $\mathrm{n} \cdot{ }^{*} 9 \mathrm{C}>\mathrm{T}$ & 262616 & 2 & 505 & 0.001923 & $\begin{array}{l}\text { European } 0.003114 \\
\text { (1) }\end{array}$ & $\begin{array}{l}\text { F551, F691, F819, F1127, } \\
\text { F1172, F1288, F2089, } \\
\text { F2143, F2427, F2816, } \\
\text { AGS2871, DiF_1, Osman } \\
\text { et al (2) }\end{array}$ \\
\hline g.8076766G>C & rs75008470 & n. $\star 5 C>G$ & 262552 & 0 & 159 & 0.0006056 & $\begin{array}{l}\text { European } 0.001019 \\
(0)\end{array}$ & $\begin{array}{l}\text { F285, F343, F362, F426, } \\
\text { F433, F445, F446 (hom), } \\
\text { F454, F1722, F2380, } \\
\text { F2474, F2737 }\end{array}$ \\
\hline g.8076770G>A & rs117595965 & n. ${ }^{*} 1 C>T$ & 262762 & 5 & 1328 & 0.005054 & $\begin{array}{l}\text { Ashkenazi Jewish } \\
0.01577 \text { (1) }\end{array}$ & $\begin{array}{l}\text { F414, F564, F780, F819, } \\
\text { F1722, Pessoa et al (1) }\end{array}$ \\
\hline g.8076776G>C & rs746503581 & n.131C>G & 263148 & 0 & 4 & 0.00001520 & $\begin{array}{l}\text { European } \\
0.00003231(0)\end{array}$ & $\begin{array}{l}\text { F309, F521, F780, F1172, } \\
\text { F1968 }\end{array}$ \\
\hline g.8076776G >T & & n.131C>A & 263148 & 0 & 0 & Novel & Novel & N8058 \\
\hline g.8076777A>G & & n.130T>C & 231804 & 0 & 2 & 0.000008628 & $\begin{array}{l}\text { South Asian } \\
0.00006610(0)\end{array}$ & F1424 \\
\hline g.8076780G>C & rs374135155 & n.127C>G & 231700 & 0 & 10 & 0.00004316 & $\begin{array}{l}\text { South Asian } \\
0.0001323(0)\end{array}$ & F445, F551 \\
\hline g.8076781G>A & rs144429028 & n.126C $>T$ & 263122 & 0 & 31 & 0.0001178 & Other $0.0002871(0)$ & F564 \\
\hline g.8076803C>T & rs201686383 & n.104G $>A$ & 263390 & 0 & 110 & 0.0004176 & $\begin{array}{l}\text { European } 0.0006859 \\
(0)\end{array}$ & F521 \\
\hline g.8076804C>T & rs562912181 & n.103G >A & 232002 & 0 & 4 & 0.00001724 & $\begin{array}{l}\text { South Asian } \\
0.00006599(0)\end{array}$ & F906, Iwama et al (1) \\
\hline g.8076807A $>C$ & & n.100T>G & 232038 & 0 & 0 & Novel & Novel & F1127 \\
\hline g.8076825T>C & rs779456932 & n. $82 A>G$ & 263450 & 0 & 18 & 0.00006832 & Other $0.0001434(0)$ & $\begin{array}{l}\text { F330, F334, F465, Jin et } \\
\text { al (1), Hermens et al. (1) }\end{array}$ \\
\hline g.8076826C>G & rs772667974 & n.81G >C & 232082 & 0 & 0 & Novel & Novel & F281 \\
\hline
\end{tabular}

This article is protected by copyright. All rights reserved. 


\begin{tabular}{|c|c|c|c|c|c|c|c|c|}
\hline g.8076826C $>\mathrm{T}$ & rs772667974 & n.81G >A & 232082 & 0 & 11 & 0.00004740 & $\begin{array}{l}\text { European } \\
0.00007372(0)\end{array}$ & $\begin{array}{l}\text { F426, F730, F1445, } \\
\text { F2036, F2089 }\end{array}$ \\
\hline g.8076832T>G & rs1400162090 & n. $75 A>C$ & 31392 & 0 & 1 & 0.00003186 & $\begin{array}{l}\text { European } \\
0.00006481(0)\end{array}$ & F2689 \\
\hline g.8076832T>C & & n. $75 A>G$ & 232094 & 0 & 4 & 0.00001723 & $\begin{array}{l}\text { East Asian } \\
0.00005688(0)\end{array}$ & F278 \\
\hline g.8076833C>T & rs372721948 & n.74G >A & 263478 & 0 & 16 & 0.00006073 & $\begin{array}{l}\text { South Asian } \\
0.00009898(0)\end{array}$ & F2243 \\
\hline g.8076834A>C & & n.73T>G & 232092 & 0 & 0 & Novel & Novel & F2474 \\
\hline g.8076835T>C & rs201558321 & n. $72 A>G$ & 232094 & 0 & 16 & 0.00006894 & $\begin{array}{l}\text { East Asian } \\
0.0001706(0)\end{array}$ & $\begin{array}{l}\text { F331, F2427, F2480, } \\
\text { Iwama et al (2), Osman et } \\
\text { al (3) }\end{array}$ \\
\hline g.8076843C>T & rs372252345 & n. $64 \mathrm{G}>\mathrm{A}$ & 263458 & 0 & 35 & 0.0001328 & Latino $0.0005690(0)$ & $F 2143$ \\
\hline g.8076846T>C & rs750457525 & n. $61 \mathrm{~A}>\mathrm{G}$ & 263474 & 0 & 16 & 0.00006073 & Other $0.0001434(0)$ & $\begin{array}{l}\text { F414, F641, Pessoa et al } \\
\text { (1) }\end{array}$ \\
\hline g.8076846_8076847insA & rs757706428 & n.60_61insT & 263474 & 0 & 2 & 0.000007591 & $\begin{array}{l}\text { African } 0.00008828 \\
\text { (0) }\end{array}$ & F465 \\
\hline g.8076847C>G & & n. $60 \mathrm{G}>\mathrm{C}$ & 232080 & 0 & 0 & Novel & Novel & DiF_1 \\
\hline g.8076848A>C & rs752108301 & n.59T>G & 263468 & 0 & 0 & Novel & Novel & F1288 \\
\hline g.8076849T>C & rs755495846 & n.58A $>G$ & 263490 & 0 & 6 & 0.00002277 & $\begin{array}{l}\text { South Asian } \\
0.00009898(0)\end{array}$ & F691, F2816 \\
\hline g.8076849dup & & n.58dup & 263490 & 0 & 0 & Novel & Novel & F337 \\
\hline g.8076850C >T & rs886039784 & n.57G $>A$ & 263492 & 0 & 7 & 0.00002657 & $\begin{array}{l}\text { African } 0.00004411 \\
\text { (0) }\end{array}$ & $\begin{array}{l}\text { F285, F2494, Taglia et al } \\
\text { (2) }\end{array}$ \\
\hline g.8076850C>A & & $\mathrm{n} .57 \mathrm{G}>\mathrm{T}$ & 263492 & 0 & 0 & Novel & Novel & F2380 \\
\hline g.8076851dup & rs775673578 & n.56dup & 232100 & 0 & 2 & 0.000008617 & $\begin{array}{l}\text { African } 0.00007165 \\
(0)\end{array}$ & F172, F2737 \\
\hline g.8076865C>T & rs148909909 & n. $42 G>A$ & 263436 & 0 & 282 & 0.001070 & African $0.003398(0)$ & F766 \\
\hline g.8076868C>G & rs200458465 & n.39G $>C$ & 263390 & 0 & 33 & 0.0001253 & $\begin{array}{l}\text { East Asian } \\
0.0004702(0)\end{array}$ & $\begin{array}{l}\text { F906, F2689, Iwama et al } \\
\text { (6), Iwasaki (1) }\end{array}$ \\
\hline g.8076868C $>A$ & & n.39G $>T$ & 232004 & 0 & 2 & 0.000008621 & $\begin{array}{l}\text { East Asian } \\
0.00005688(0)\end{array}$ & F1954 (Hom) \\
\hline
\end{tabular}

This article is protected by copyright. All rights reserved. 


\begin{tabular}{|c|c|c|c|c|c|c|c|c|}
\hline g.8076883G >A & rs368022715 & n.24C>T & 263352 & 0 & 84 & 0.0003190 & $\begin{array}{l}\text { African } 0.0007062 \\
\text { (0) }\end{array}$ & F856, Iwama et al (1) \\
\hline g.8076887G >A & rs545394298 & n.20C>T & 231710 & 0 & 7 & 0.00003021 & $\begin{array}{l}\text { East Asian } \\
0.00005692(0)\end{array}$ & $\begin{array}{l}\text { F362, F433, F2054, } \\
\text { N11301 }\end{array}$ \\
\hline g.8076899C>G & rs201266955 & n.8G $>C$ & 262710 & 0 & 4 & 0.00001523 & $\begin{array}{l}\text { African } 0.00004413 \\
\text { (0) }\end{array}$ & $\begin{array}{l}\text { F278, F344 (Hom), Hild_1 } \\
\text { (Hom) }\end{array}$ \\
\hline g.8076899C>T & rs201266955 & n.8G $>A$ & 262710 & 4 & 724 & 0.002756 & $\begin{array}{l}\text { European (Finnish) } \\
0.01686 \text { (3) }\end{array}$ & $\mathrm{F} 330$ \\
\hline g.8076904G>A & rs117735243 & $\mathrm{n} .3 \mathrm{C}>\mathrm{T}$ & 262476 & 2 & 389 & 0.001482 & $\begin{array}{l}\text { European (Finnish) } \\
0.006487 \text { (0) }\end{array}$ & $\begin{array}{l}\text { F281, F309, F1445, } \\
\text { F2494, Iwama et al (2), } \\
\text { Osman et al (1) }\end{array}$ \\
\hline g.8076904G >T & rs117735243 & n. $3 C>A$ & 231102 & 0 & 1 & 0.000004327 & $\begin{array}{l}\text { European } \\
0.000009243(0)\end{array}$ & F766, N11301 \\
\hline g.8076905A>G & rs368446612 & $\mathrm{n} .2 \mathrm{~T}>\mathrm{C}$ & 230692 & 0 & 5 & 0.00002167 & $\begin{array}{l}\text { European } \\
0.00003702(0)\end{array}$ & F337 \\
\hline g.8076912C>T & rs200531412 & n. $-6 G>A$ & 262340 & 0 & 224 & 0.0008539 & $\begin{array}{l}\text { East Asian } 0.001780 \\
(0)\end{array}$ & $\begin{array}{l}\text { F1424, F1968, F2243, } \\
\text { N8058 }\end{array}$ \\
\hline g.8076885_8076913dup & & n.-7_22dup & 231956 & 0 & 0 & Novel & Novel & F343 \\
\hline g.8076955_8076960del & rs886039783 & n.-54_-49del & 224458 & 0 & 0 & Novel & Novel & F454, F2871 \\
\hline
\end{tabular}

Table 2. List of SNORD118 variants identified by patient(s) with LCC. Genomic coordinates of variants identified and their frequency on gnomAD are given. Families in this study in which these variants are listed. Note is also made of variants and families identified in mutationpositive cases published by other groups (with the numbers of probands in these papers given in brackets.

† All genomic coordinates should be preceded by Chr17(GRCh37):

^ SNORD118 NR_033294.1

Hom = homozygous; Het = heterozygous; gnomAD = Genome Aggregation Database

* Number of homozygote alleles recorded in gnomAD for each variant

** Number of heterozygote alleles recorded in gnomAD for each variant

‡ Number in brackets is the number of homozygote alleles recorded in the population with the highest frequency on gnomAD

$\S$ Deletion extends beyond these boundaries, but boundaries have not been fully defined

This article is protected by copyright. All rights reserved. 
Note: F344 was homozygous for both n.8G>C, and n.113C>T. n.8G>C was considered most likely to be the pathogenic mutation given that is seen in other families.

Note: F2089 also carried a $n .119 G>T$ in combination with $n .{ }^{*} 9 \mathrm{C}>\mathrm{T}$ and $\mathrm{n} .81 \mathrm{G}>\mathrm{A}$. The latter two are thought likely to be the pathogenic mutations given that they are seen in other families. Parental DNA was not available to test phase. 


\section{University Library}

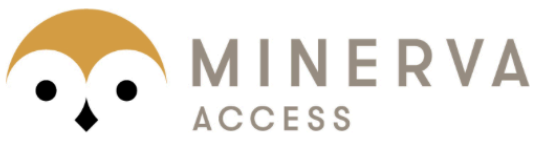

\section{A gateway to Melbourne's research publications}

Minerva Access is the Institutional Repository of The University of Melbourne

\section{Author/s:}

Crow, YJ;Marshall, H;Rice, G;Seabra, L;Jenkinson, EM;Baranano, K;Battini, R;Berger, A;Blair, E;Blauwblomme, T;Bolduc, F;Boddaert, N;Buckard, J;Burnett, H;Calvert, S;Caumes, R;Ng, AC-H;Chiang, D;Clifford, DB;Cordelli, DM;Burca, A;Demic, N;Desguerre, I;De Waele, L;Di Fonzo, A;Dunham, SR;Dyack, S;Elmslie, F;Ferrand, M;Fisher, G;Karimiani, EG;Ghoumid, J;Gibbon, F;Goel, H;Hilmarsen, HT;Hughes, I;Jacob, A;Jones, EA;Kumar, R;Leventer, RJ;MacDonald, S;Maroofian, R;Mehta, SG;Metz, I;Monfrini, E;Neumann, D;Noetzel, M;O'Driscoll, M;Ounap, K;Panzer, A;Parikh, S;Prabhakar, P;Ramond, F;Sandford, R;Saneto, R;Soh, C;Stutterd, CA;Subramanian, GM;Talbot, K;Thomas, RH;Toro, C;Touraine, R;Wakeling, E;Wassmer, E;Whitney, A;Livingston, JH;O'Keefe, RT;Badrock, AP

Title:

Leukoencephalopathy with calcifications and cysts: Genetic and phenotypic spectrum

Date:

2020-10-07

\section{Citation:}

Crow, Y. J., Marshall, H., Rice, G., Seabra, L., Jenkinson, E. M., Baranano, K., Battini, R., Berger, A., Blair, E., Blauwblomme, T., Bolduc, F., Boddaert, N., Buckard, J., Burnett, H., Calvert, S., Caumes, R., Ng, A. C. -H., Chiang, D., Clifford, D. B. ,... Badrock, A. P. (2020). Leukoencephalopathy with calcifications and cysts: Genetic and phenotypic spectrum. AMERICAN JOURNAL OF MEDICAL GENETICS PART A, 185 (1), pp.15-25. https://doi.org/10.1002/ajmg.a.61907.

Persistent Link:

http://hdl.handle.net/11343/276417 